KREATIF : Jurnal Ilmiah Prodi Manajemen Universitas Pamulang, Vol. 8, No.2, Desember 2020

KREATIF

Jurnal IImiah
@ Prodi Manajemen Fakultas Ekonomi Universitas Pamulang

ISSN : 2339 - 0689, E-ISSN : 2406-8616

J. KREATIF, Vol. 8 No.2, Desember 2020 (Halaman 102-111)

Tersedia Online di :http://openjournal.unpam.ac.id/index.php/kreatif

\title{
PENGARUH MOTIVASI TERHADAP KINERJA PEGAWAI PADA KECAMATAN CIPUTAT TIMUR KOTA TANGERANG SELATAN
}

\author{
Sri Mardiana ${ }^{1}$, Vega Anismadiyah ${ }^{2}$, Amun Soepandi $^{3}$ \\ ${ }^{1-3}$ Program Studi Manajemen Fakultas Ekonomi Universitas Pamulang \\ email : dosen02065@unpam.ac.id,dosen02218@unpam.ac.id, dosen01878@unpam.ac.id
}

\begin{abstract}
ABSTRAK
Tujuan dari penelitian ini ialah untuk mengetahui motivasi pada pegawai kecamatan Ciputat Timur, mengetahui kinerja pada pegawai kecamatan Ciputat Timur, mengetahui pengaruh motivasi terhadap kinerja pada pegawai Kecamatan Ciputat Timur.

Jenis penelitian ini adalah kuantitatif deskriptif dengan jumlah sampel sebanyak 55 pegawai Aparatur Sipil Negara (ASN). Data diperoleh dengan memberikan kuesioner dan mengadakan wawancara langsung kepada pegawai. Sedangkan metode analisis data yang digunakan adalah regresi linear sederhana, uji koefisien determinasi dan uji signifikansi.

Hasil penelitian yang didapatkan yaitu variabel bebas yaitu Motivasi (X) berpengaruh positif dan signifikan terhadap variabel terikat yaitu Kinerja Pegawai (Y) sebesar 0,249 dengan Nilai koefisien determinasi (KD) adalah 60,8\% sisanya dipengaruhi oleh faktor yang tidak diteliti.
\end{abstract}

Kata Kunci : Motivasi dan Kinerja Pegawai.

\section{ABSTRACT}

The purpose of this study was to determine the motivation of employees of East Ciputat sub-district, to know the performance of East Ciputat sub-district employees, to determine the effect of motivation on the performance of employees of East Ciputat District.

This type of research is descriptive quantitative with a sample size of 55 employees of the State Civil Apparatus (ASN). Data obtained by giving questionnaires and conducting direct interviews with employees. While the data analysis method used is simple linear regression, test the coefficient of determination and significance test.

The results obtained are the independent variable, namely Motivation (X) has a positive and significant effect on the dependent variable, namely Employee Performance $(Y)$ of 0.249 with the coefficient of determination $(K D)$ is $60.8 \%$, the rest is influenced by factors not researched.

Keywords: Motivation, Employee Performance, Kecamatan Ciputat Timur.

\section{PENDAHULUAN}

\section{A. Latar Belakang Masalah}

Kualitas manusia sebagai seorang pekerja, karyawan ataupun pegawai sangat berpengaruh terhadap maju atau mundur maupun berkembang atau tidaknya suatu perusahaan. Tidak bisa dipungkiri lagi, di dalam sebuah perusahaan, manusia adalah 
KREATIF : Jurnal Ilmiah Prodi Manajemen Universitas Pamulang, Vol. 8, No.2, Desember 2020

sumber daya yang sangat penting, karena manusia memiliki berbagai kemampuan yang sangat dibutuhkan oleh sebuah perusahaan untuk mencapai tujuan perusahaan. Tetapi manusia juga punya berbagai macam kebutuhan yang harus dan ingin dipenuhi. Kebutuhan inilah yang memotivasi seorang manusia untuk bekerja.

Motivasi merupakan suatu hal yang mendorong seseorang mau menggunakan seluruh kemampuannya untuk bekerja agar bisa mencapai tujuannya. Dengan motivasi yang baik dan tepat, seorang pegawai akan semakin menyadari pentingnya kerja yang optimal, disiplin dan profesional.

Untuk motivasi eksternal, baik dari atasan maupun dari rekan kerja, masih kurang berjalan di instansi ini. Misalnya, setelah selesai waktu istirahat masih ada pegawai yang belum masuk kantor sementara pekerjaan sudah menumpuk dan masyarakat yang akan mengurus administrasi sudah banyak berdatangan sehingga harus menunggu lama karena tidak adanya pegawai yang melayani. Motivasi eksternal perlu diberikan kepada pegawai sehingga mereka bisa bekerja lebih disiplin dan lebih profesional.

Kecamatan merupakan salah satu birokrasi pemerintah yang langsung melayani masyarakat. Salah satu tugas kecamatan ialah membina desa atau kelurahan. Sebagai sebuah organisasi yang melayani kehidupan masyarakat dengan penuh dinamika, kecamatan mengalami banyak masalah sebagai organisasi administratif. Masalah yang dihadapi pihak kecamatan lebih banyak yang bersifat manajerial. Permasalahan biasanya berkaitan erat dengan banyaknya jumlah penduduk, keberagaman pendidikan, umur, kemampuan ekonomi, asal-usul. Kelancaran pelaksanaannya sangat tergantung pada kinerja pegawai, baik pegawai yang berstatus ASN (Aparatur Sipil Negara) maupun pegawai yang bersifat honorer, agar efektifitas dan efisiensi pelayanan dapat tercapai.

Menurut penulis, motivasi yang paling penting dan paling berpengaruh adalah motivasi dari dalam diri sendiri (inner motivation), tetapi motivasi dari luar tetap diperlukan untuk meningkatkan kinerja pegawai. Dengan memotivasi diri sendiri dan mendapatkan motivasi dari pihak luar baik keluarga, pimpinan, perusahan, rekan kerja dan lain-lain, maka akan tumbuh pribadi yang profesional dan produktif.

Kinerja merupakan hasil dari sebuah kerja, baik secara kualitas maupun kuantitas, yang dicapai oleh seseorang dalam melaksanakan tugasnya sesuai dengan tanggung jawab yang diberikan kepadanya. Melihat pentingnya kinerja pegawai sebagai persyaratan untuk meningkatkan kualitas pelayanan administrasi, maka penulis tertarik meneliti pada Kecamatan Ciputat Timur dengan judul "Pengaruh Motivasi Terhadap Kinerja Pegawai Pada Kecamatan Ciputat Timur Kota Tangerang Selatan".

\section{B. Rumusan Masalah}

Rumusan masalah dalam penelitian ini adalah sebagai berikut:

1) Bagaimana motivasi pada pegawai kecamatan Ciputat Timur Tangerang Selatan?

2) Bagaimana kinerja pada pegawai Kecamatan Ciputat Timur Tangerang Selatan?

3) Bagaimana pengaruh motivasi terhadap kinerja pada pegawai kecamatan Ciputat Timur Tangerang Selatan?

\section{Tujuan}

Sesuai dengan rumusan masalah yang telah dijelaskan sebelumnya, penelitian ini memiliki tujuan sebagai berikut: 
KREATIF : Jurnal Ilmiah Prodi Manajemen Universitas Pamulang, Vol. 8, No.2, Desember 2020

1) Untuk mengetahui motivasi pada pegawai kecamatan Ciputat Timur Tangerang Selatan.

2) Untuk mengetahui kinerja pada pegawai Kecamatan Ciputat Timur Tangerang Selatan.

3) Untuk mengetahui pengaruh motivasi terhadap kinerja pada pegawai kecamatan Ciputat Timur Tangerang Selatan.

\section{TINJAUAN PUSTAKA}

\section{A. Motivasi}

Motivasi berhubungan dengan kekuatan dan dorongan yang ada dalam diri manusia yang mempengaruhi individu untuk mencapai tujuan tertentu. Meskipun motivasi tidak terlihat dari luar, namun motivasi menjadi hal yang dapat mendorong seseorang untuk mencapai tujuan tertentu.

Hasibuan (2015:99) berpendapat bahwa "ada dua jenis motivasi yang diberikan kepada, yaitu:

1) Motivasi positif

Motivasi yang diberikan bersifat positif. Misalnya, seorang manajer memberikan memotivasi kepada bawahannya dengan memberikan hadiah atau penghargaan kepada mereka yang berprestasi baik. Dengan adanya motivasi positif tersebut, semangat kerja bawahan akan meningkat, karena pada dasarnya manusia senang akan penghargaan dan pengakuan.

2) Motivasi negatif

Motivasi yang diberikan bersifat negatif. Misalnya, seorang manajer memberikan motivasi kepada bawahannya dengan memberikan teguran atau hukuman kepada mereka yang pekerjaannya kurang baik (prestasi rendah). Dengan adanya motivasi negatif tersebut, semangat kerja bawahan akan meningkat karena ingin menghindari hukuman tadi."

\section{B. Kinerja}

Moeheriono (2012:95) dalam Ma'ruf Abdullah (2014:3) berpendapat bahwa "kinerja atau performance merupakan suatu gambaran mengenai tingkat pencapaian pelaksanaan suatu program kegiatan atau kebijakan dalam mewujudkan sasaran, tujuan, visi, dan misi organisasi yang dituangkan melalui perencanaan strategis suatu organisasi”.

Menurut Wirawan (2009), "kinerja karyawan atau pegawai dipengaruhi oleh tiga faktor yaitu:

1) Faktor lingkungan eksternal yaitu faktor di luar perusahaan misalnya kehidupan ekonomi, kehidupan politik, kehidupan sosial, budaya dan agama, masyarakat, dan kompetitor.

2) Faktor internal karyawan yaitu faktor dari dalam diri karyawan sendiri seperti bakat dan kepribadian, kreativitas, pengetahuan dan keterampilan, kompetensi, pengalaman kerja, keadaan fisik, keadaan psikologi diantaranya etos kerja, disiplin kerja, motivasi kerja, semangat kerja, stres kerja, kepemimpinan, kepuasan kerja, dan loyalitas).

3) Faktor lingkungan internal yaitu faktor dari dalam perusahaan seperti visi, misi dan tujuan perusahaan, kebijakan perusahaan, teknologi, strategi perusahaan, sistem manajemen, kompensasi, kepemimpinan, modal, budaya organisasi, iklim organisasi dan rekan kerja".

C. Pengaruh motivasi kerja terhadap kinerja karyawan

Seorang pegawai membutuhkan motivasi kerja di dalam dirinya agar dapat 
KREATIF : Jurnal Ilmiah Prodi Manajemen Universitas Pamulang, Vol. 8, No.2, Desember 2020

memberikan hasil pekerjaaan dengan kualitas dan kuantitas yang baik.

Dari beberapa penjelasan tersebut, penulis menyimpulkan bahwa motivasi mempengaruhi kinerja pegawai karena dengan adanya motivasi, seorang pegawai mampu melakukan pekerjaannya secara efektif dan efisien sehingga hasil kerjanya semakin baik serta berdampak pada tercapainya tujuan perusahaan secara optimal.

\section{Kerangka berpikir}

Penjelasan tersebut dapat digambarkan melalui sebuah skema sistematis sebagai berikut:

Gambar 1. Kerangka Berpikir

\section{PENGARUH MOTIVASI TERHADAP KINERJA PEGAWAI PADA KECAMATAN CIPUTAT TIMUR}

\begin{tabular}{|c|c|}
\hline MOTIVASI (Variabel X) & KINERJA (Variabel Y) \\
\hline Kemampuan pribadi & Tanggung Jawab \\
\hline Tingkat pendidikan & Loyalitas \\
\hline Kebutuhan karyawan & Kejujuran \\
\hline Kompensasi yang memadai & Kedisiplinan \\
\hline Penghargaan Prestasi & Keahlian \\
\hline $\begin{array}{l}\text { Marihot Manullang } \\
\quad(2015: 176)\end{array}$ & $\begin{array}{r}\text { Wirawan } \\
(2015: 136)\end{array}$ \\
\hline
\end{tabular}

\section{E. Hipotesis penelitian}

Berdasarkan kajian teori dan kerangka berpikir yang relevan maka dapat dikemukakan hipotesis penelitian sebagai berikut:

$H 0$ : Diduga tidak terdapat pengaruh motivasi terhadap kinerja pegawai

$H_{\mathrm{a}}$ : Diduga terdapat pengaruh motivasi terhadap kinerja pegawai

\section{METODE PENELITIAN}

\section{A. Jenis Penelitian}

Metode yang digunakan dalam penelitian ini adalah metode kuantitatif deskriptif. Menurut Sugiyono (2013:13) "Penelitian kuantitatif diartikan sebagai metode penelitian yang berlandaskan pada filsafat positivisme yang digunakan untuk meneliti pada populasi atau sampel tertentu". Menurut Sugiyono (2013:206) "Statistik deskriptif adalah statistik untuk menganalisa data dengan cara menggambarkan data yang telah terkumpul sebagaimana adanya tanpa bermaksud membuat kesimpulan yang berlaku untuk umum atau generalisasi".

\section{B. Populasi dan sampel}

Populasi yang digunakan sesuai dengan jumlah Aparatur Sipil Negara yang bekerja di kecamatan Ciputat Timur yaitu sejumlah 55 pegawai. Penelitian ini menggunakan sampel jenuh, artinya sampel melibatkan seluruh populasi yaitu 55 
KREATIF : Jurnal Ilmiah Prodi Manajemen Universitas Pamulang, Vol. 8, No.2, Desember 2020

responden.

C. Teknik Pengumpulan Data

Penelitian ini menggunakan teknik observasi, wawancara, studi pustaka dan kuesioner.

D. Uji Instrumen Angket

1) Uji Validitas Instrumen

Menurut Arikunto (2002: 144-145), "Validitas adalah suatu ukuran yang menunjukkan tingkat kevalidan atau kesahihan suatu instrumen. Instrumen yang valid memiliki validitas yang tinggi”.

2) Uji Reliabilitas

Menurut Suharsimi Arikunto (2002:154) "Reliabilitas menunjukkan bahwa suatu instrumen cukup dapat dipercaya untuk digunakan sebagai alat pengumpul data karena instrumen tersebut sudah baik".

3) Uji Korelasi Product Moment Yaitu suatu pengujian yang dilakukan untuk menguji hipotesis hubungan antara satu variabel bebas dengan satu variabel terikat dalam penelitian.

E. Teknik Analisis Data

1) Regresi Linier Sederhana

Penelitian ini menggunakan metode analisis deskriptif. Regresi Linear Sederhana digunakan untuk mengetahui pengaruh variabel bebas terhadap variabel terikat.

2) Uji Normalitas

Untuk menguji apakah variabel bebas dan variabel terikat berdistribusi normal atau tidak normal.

3) Uji Koefisien Determinasi

Untuk menunjukkan seberapa besar variabel bebas yang digunakan mampu menjelaskan variabel terikat.

4) Uji Signifikansi

Untuk menguji tingkat signifikansi antara variabel bebas (motivasi) dengan variabel terikat (kinerja).

Dengan perumusan dan pengujian hipotesisnya adalah :

Ho : Diduga tidak terdapat pengaruh positif dan signifikan antara motivasi kerja terhadap kinerja pwgawai.

Ha : Diduga terdapat pengaruh positif dan signifikan antara motivasi kerja terhadap kinerja pegawai.

Terdapat hubungan yang positif dan signifikan apabila nilai $t_{\text {hitung }}>t_{\text {tabel. }}$

\section{HASIL DAN PEMBAHASAN}

A. Uji Validitas dan Reliabilitas

1. Uji Validitas Variabel Motivasi

Hasil Analisis Item Instrumen Motivasi

\begin{tabular}{|c|c|c|c|}
\hline \multicolumn{4}{|c|}{ Uji Validitas Variabel X } \\
\hline No & rhitung & \multicolumn{1}{c|}{ rtabel } & Keputusan \\
\hline Pert.1 & 0,545 & 0,265 & Valid \\
\hline Pert.2 & 0,609 & 0,265 & Valid \\
\hline Pert.3 & 0,656 & 0,265 & Valid \\
\hline
\end{tabular}


KREATIF : Jurnal Ilmiah Prodi Manajemen Universitas Pamulang, Vol. 8, No.2, Desember 2020

\begin{tabular}{|c|c|r|c|}
\hline Pert.4 & 0,550 & 0,265 & Valid \\
\hline Pert.5 & 0,728 & 0,265 & Valid \\
\hline Pert.6 & 0,571 & 0,265 & Valid \\
\hline Pert.7 & 0,688 & 0,265 & Valid \\
\hline Pert.8 & 0,564 & 0,265 & Valid \\
\hline Pert.9 & 0,760 & 0,265 & Valid \\
\hline Pert.10 & 0,677 & 0,265 & Valid \\
\hline
\end{tabular}

$r_{\text {hitung }}$ lebih besar dari $r_{\text {tabel }}(0,545>0,265)$ artinya variabel Motivasi valid.

\section{Uji Validitas Variabel Kinerja}

Hasil Analisis Item Instrumen Kinerja

\begin{tabular}{|c|c|c|c|}
\hline \multicolumn{4}{|c|}{ Uji Validitas Variabel Y } \\
\hline No & rhitung & rtabel & Keputusan \\
\hline Pert.1 & 0,631 & 0,265 & Valid \\
\hline Pert.2 & 0,534 & 0,265 & Valid \\
\hline Pert.3 & 0,695 & 0,265 & Valid \\
\hline Pert.4 & 0,674 & 0,265 & Valid \\
\hline Pert.5 & 0,444 & 0,265 & Valid \\
\hline Pert.6 & 0,436 & 0,265 & Valid \\
\hline Pert.7 & 0,514 & 0,265 & Valid \\
\hline Pert.8 & 0,431 & 0,265 & Valid \\
\hline Pert.9 & 0,655 & 0,265 & Valid \\
\hline Pert.10 & 0,525 & 0,265 & Valid \\
\hline
\end{tabular}

$r_{\text {hitung }}$ lebih besar daripada $r_{\text {tabel }}(0,631>0,265)$ artinya variabel Kinerja valid.

3. Uji Reliabilitas Variabel Motivasi dan Kinerja

Hasil Analisis Uji Reliabilitas

\begin{tabular}{|c|c|c|c|}
\hline Variabel & Reabilitas & Cronbach alpha & Keterangan \\
\hline Motivasi & 0,746 & 0,6 & Reliabel \\
\hline $\begin{array}{c}\text { Kinerja } \\
\text { Pegawai }\end{array}$ & 0,725 & 0,6 & Reliabel \\
\hline
\end{tabular}

$r_{\text {ca motivasi }}$ lebih besar dari $r_{\text {catabel motivasi }}(0,746>0,6)$ sehingga variabel motivasi dikatakan reliabel.

$r_{\text {ca kinerja }}$ lebih besar dari $r_{\text {catabel kinerja }}(0,725>0,6)$ sehingga variabel kinerja dikatakan reliable.

\section{B. Pengaruh Motivasi Terhadap Kinerja Pegawai}

1. Uji Korelasi

$$
r_{x y}=\frac{n \Sigma X Y-(\Sigma X)(\Sigma Y)}{\sqrt{\left\{( n \Sigma X ^ { 2 } - ( \Sigma X ) ^ { 2 } \} \cdot \left\{\left(n \Sigma Y^{2}-(\Sigma Y)^{2}\right\}\right.\right.}}
$$


KREATIF : Jurnal Ilmiah Prodi Manajemen Universitas Pamulang, Vol. 8, No.2, Desember 2020

\section{Pedoman Untuk Memberikan Interpretasi Koefisien Korelasi}

\begin{tabular}{|c|c|}
\hline Interval koefisien & Tingkat hubungan \\
\hline $0,00-0,199$ & Sangat rendah \\
$0,20-0,399$ & Rendah \\
$0,40-0,599$ & Sedang \\
$0,60-0,799$ & Kuat \\
$0,80-0,1000$ & Sangat kuat \\
\hline
\end{tabular}

Korelasi Product Moment di dapat nilai $r_{x y}$ sebesar 0,602 yang artinya terdapat hubungan positif dan kuat antara Motivasi terhadap Kinerja pegawai di Kantor Kecamatan Ciputat Timur Kota Tangerang Selatan.

\section{Analisis Regresi Linear Sederhana}

Analisis regresi bertujuan mengetahui besarnya pengaruh Motivasi terhadap Kinerja pada Kantor Kecamatan Ciputat Timur Kota Tangerang Selatan.

$$
b=\frac{n \Sigma X Y-(\Sigma X)(\Sigma Y)}{\left(n \Sigma X^{2}-(\Sigma X)^{2}\right.}
$$

$$
b=\frac{55 \times 82261 \square(2143)(2097)}{\square(214) 2}
$$

$$
\left(55 \times 85723 \square(2143)^{2}\right.
$$

$$
b=\frac{4524355 \square(4493871)}{(4714765) \square 4592449}
$$

$b=\underline{30484}$

122316

$b=0,249$

$$
\mathrm{a}=\frac{\sum y}{n}-\frac{b \sum x}{n}
$$

$\mathrm{a}=\frac{2097}{55}-\frac{(0,249(2143)}{55}$

$a=\frac{2097}{55}-\frac{533,607}{55}$

$\mathrm{a}=\underline{1563,393}$

$$
\mathrm{a}=28,425
$$

$\mathrm{Y}=28,425+0.249 \mathrm{X}$

Berdasarkan hasil perhitungan diatas dapat dijelaskan sebagai berikut :

1. Nilai konstanta intersep sebesar 28,425 merupakan kontanta (a). Menyatakan 
KREATIF : Jurnal Ilmiah Prodi Manajemen Universitas Pamulang, Vol. 8, No.2, Desember 2020

bahwa kalau $\mathrm{X}=0$, maka nilai $\mathrm{Y}=28,425$

2. Nilai Koefisien regresi variable Motivasi (X) terhadap Kinerja Pegawai

(Y) adalah sebesar 0,249. Hal ini berarti Motivasi (X) berpengaruh terhadap Kinerja pegawai sebesar 0,249.

\section{Koefisien Determinasi}

Dilakukan untuk mengetahui persentase kontribusi motivasi (X) terhadap kinerja (Y).

$\mathrm{KD}=\mathrm{r}^{2} \times 100 \%$

$\mathrm{KD}=0,780^{2} \times 100 \%$

$\mathrm{KD}=0,608 \times 100 \%$

$\mathrm{KD}=60,8 \%$

Nilai koefisien determinasi $(\mathrm{KD})=60,8 \%$, artinya kontribusi variabel Motivasi $(\mathrm{X})$ berpengaruh terhadap variabel Kinerja pegawai (Y) sebesar 60,8\% sedangkan selebihnya yaitu $(100 \%-60,8 \%)=39,2 \%$ dipengaruhi oleh faktor lain yang tidak diteliti penulis.

\section{Uji Hipotesis}

\section{a. Rumusan hipotesis}

H0 : Diduga tidak terdapat pengaruh motivasi terhadap kinerja pegawai

$\mathrm{Ha}$ : Diduga terdapat pengaruh motivasi terhadap kinerja pegawai

\section{Uji Signifikasi}

$$
\begin{aligned}
& t_{\text {hitung }}=\frac{r s \sqrt{k-2}}{\sqrt{1-r^{2}}} \\
& t_{\text {hitung }}=\frac{0,780 \sqrt{55-2}}{\sqrt{1-0,780^{2}}} \\
& t_{\text {hitung }}=\frac{0,780 \sqrt{53}}{\sqrt{1-0,608}} \\
& t_{\text {hitung }}=\frac{0,780(7,280)}{\sqrt{0,392}}
\end{aligned}
$$


KREATIF : Jurnal Ilmiah Prodi Manajemen Universitas Pamulang, Vol. 8, No.2, Desember 2020

$$
\begin{aligned}
& t_{\text {hitung }}=\frac{5,678}{\sqrt{0,392}} \\
& t_{\text {hitung }}=\frac{5,678}{0,626} \\
& t_{\text {hitung }}=9,070
\end{aligned}
$$

\section{Tingkat Signifikasi}

$$
\begin{aligned}
T_{\text {tabel }}= & t(\alpha ; n-2) \\
& =9,070(0,05 ; 53) \\
& =1,674
\end{aligned}
$$

Karena thitung lebih besar dari pada ttabel $(9,070>1,674)$ maka H0 ditolak dan Ha diterima, jadi terdapat pengaruh yang positif dan signifikan antara motivasi terhadap kinerja pegawai pada kantor Kecamatan Ciputat Timur Kota Tangerang Selatan.

\section{KESIMPULAN DAN SARAN}

\section{Kesimpulan}

1) Motivasi mampu mempengaruhi Kinerja pegawai secara positif dan signifikan, Artinya bahwa jika motivasi pegawai Kecamatan Ciputat Timur baik, maka kinerjanya juga akan baik. Sebaliknya, jika motivasi pegawai Kecamatan Ciputat Timur rendah, maka kinerjanya juga akan rendah.

2) Berdasarkan analisis Regresi Regresi Sederhana di peroleh hasil $Y=28,425+0.249 \mathrm{X}$ artinya bahwa tanpa Motivasi, Kinerja tetap terbentuk sebesar 28,425

3) Nilai Koefisien Determinasi sebesar $60,8 \%$ artinya motivasi berkontribusi sebanyak $60,8 \%$, sementara sisanya sebesar $39,2 \%$ dijelaskan oleh variabel lain diluar penelitian ini.

\section{Saran}

1) Motivasi karyawan Kecamatan Ciputat Timur dalam bekerja melayani masyarakat sudah optimal dan sebaiknya motivasi ini tetap di pertahankan agar kinerja pegawai semakin baik.

2) Untuk peneliti yang akan datang dapat kiranya menambah variabel penelitian supaya hasil lebih maksimal.

\section{DAFTAR PUSTAKA}

Abdullah. (2014). Manajemen dan Evaluasi Kinerja Karyawan. Yogyakarta: Aswaja Presindo. 
KREATIF : Jurnal Ilmiah Prodi Manajemen Universitas Pamulang, Vol. 8, No.2, Desember 2020

Hasibuan, Malayu SP. (2014). Manajemen Sumber Daya Manusia Edisi Revisi. Jakarta: PT Bumi Aksara.

Nurjanah, Wahyu Dewi. Januari 2017. Pengaruh Kepeminpinan dan Motivasi Terhadap Kinerja Karyawan Pada PT Sumber Bengawan Plasindo Karangayar.

Jurnal Penelitian dan Kajian Ilmiah Fakultas Ekonomi Universitas Surakarta. ISSN 2085-2215 Volume 15 No.1 Hal 50-53

Prakoso, Cathas Teguh, Akhmad Fydayeen, Masjaya. April 2016. Pengaruh Kepemimpinan dan Motivasi Kerja Terhadap Kinerja Pegawai Bagian Hukum Sekretariat Daerah Kota Samarinda. Journal Administrative $\quad$ Reform. ISSN 2387637 Volume 4 No. 3 Hal 753 - 747.

Sedarmayanti. (2015). Manajemen Sumber Daya Manusia. Bandung: PT Refika Aditama.

Sinaga, Inggrid Wahyuni, Syazhashah Putra Bahrum. November 2015. Pengaruh Kepemimpinan dan Motivasi Kerja Terhadap Kinerja Pegawai pada Pegawai

Lembaga Dewan Kawasan Perdagangan Bebas Pelabuhan Bebas Bantam Bintan

Karimun. Jurnal Akuntansi, Ekonomi dan Manajemen $\quad$ Bisnis. ISSN 2337-7887

Volume 3 No. 2 Hal 135 - 141.

Sugiyono. (2013). Metode Peelitian Kuantitatif, Kualitatif dan R\&D. Bandung: Alfabeta.

Wibowo. (2017). Manajemen Kinerja. Jakarta: Raja Grafindo Persada. 